\title{
Living With Maternal HIV: Spirituality, Depression, And Family Functioning
}

\author{
Aisha T. Asby, Ph.D., Prairie View A\&M University, USA \\ Angela M. Bowman Heads, Ph.D., University of Texas Health Science Center at Houston, USA \\ Joseph W. Dickson, Ph.D., Prairie View A\&M University, USA
}

\begin{abstract}
Risk factors such as depression and low SES often affect an HIV infected mother's ability to function within her family. Spirituality may interact with such risk factors contributing to the resiliency of these mothers. The current study explored spirituality's influence on the relationship between depression and perceptions of family functioning in African American women living with HIV. High levels of spirituality were associated with decreased psychological distress and spirituality served as a significant predictor of family cohesion. Findings from this study support the importance of spirituality in the lives of African American women living with HIV and their families.
\end{abstract}

Keywords: Spirituality; Depression; Family Functioning; HIV/AIDS

\section{INTRODUCTION}

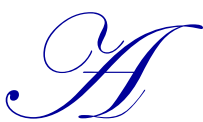

crisis, such as parental illness, can significantly affect the functioning of any family. It may alter the family structure, causing a redistribution of roles and responsibilities among various family members (Pedersen \& Revenson, 2005). If the parent is unable to fulfill his or her roles and responsibilities, extra demands may be placed on other family members including the children (Tompkins, 2007). For African American women, maintaining the family system while infected with HIV can be a very difficult task, especially when compounded by other environmental stressors such as socioeconomic status and heath care access.

Previous research has given us information on how stress can affect psychological functioning. For example, according to Utsey, Giesbrecht, Hook, and Stanard (2008), if stressful events are viewed as uncontrollable and physical (e.g., health and energy level), social (e.g., family and friends), psychological (e.g., self-esteem/selfefficacy), and material resources are perceived as lacking, an individual will be more likely to experience psychological and physiological distress. This has been found to be especially true for women who are HIV seropositive. For example, Peterson, Johnson, and Tenzek found that women, and especially mothers, living with HIV/AIDS express more isolation, depression, and suicidal thoughts than men living with the virus (2010).

Depression is known to be problematic for individuals living with HIV/AIDS and has been linked to lower immune functioning and increased mortality among individuals with other chronic illnesses (Yi et al., 2006). Consequently, depressed mothers are less able to perform typical actions with family members and are also less responsive to the needs of those family members(Murphy, Marelich, Stritto, Swendeman, \& Witkin, 2002). Although limited studies have been conducted investigating the impact of parental HIV infection, Murphy and colleagues found that among women, those who expressed higher levels of depression also indicated lower family cohesion and sociability(Murphy et al., 2002). Additionally, depressed mothers reported more difficulty performing daily tasks while their children reported having more household responsibilities.

Some depressive symptoms are linked to individuals' stigma related experiences. Stigma is the process of devaluation of people living with or associated with HIV/AIDS and is often demonstrated verbally, institutionally, or socially. Women, especially African American women, who have a positive HIV diagnosis, are more likely than their male counterparts to be stigmatized based on perceptions of promiscuity and illicit drug use related to HIV infection (Sayles, Ryan, Silver, Sarkisian, \& Cunningham, 2007). Fearful of their status being discovered by someone who would use the knowledge to discriminate against them or their children (Armistead \& Forehand, 1995), they may choose not to disclose their status(Clark, Lindner, Armistead, \& Austin, 2004). 
Despite many of the aforementioned challenges, not all mothers who are HIV infected view their relationship with their children as negative or strained. In fact, many report having healthy relationships with their children (Antle, Wells, Robyn Salter, DeMatteo, \& King, 2001; Armistead \& Forehand, 1995; Tompkins, Henker, Whalen, Axelrod, $\&$ Comer, 1999). Several factors have been found to help African-American women deal with adversity related to their HIV status. These include social support, especially from extended family relationships, and spirituality. Spirituality has been shown to be a significant factor in the HIV infected mother's ability to deal with family and social challenges related to her HIV status. Spirituality is associated with peace, calm, and feeling centered; as well as positively influencing relationships with others (Mattis, 2000; Newlin, Knafl, \& Melkus, 2002; Walulu, 2011).

Spirituality has also been found to be associated with the ability to endure HIV related stressors in the daily lives of those affected (Walulu, 2011), a sense of wellbeing and health related quality of life(Peterson, Johnson, \& Tenzek, 2010), and better psychological adaptation(Yi et al., 2006). In one study spirituality was associated with an increased quality of life for many mothers. This may have been accomplished by providing a purpose for their lives and illness while also lowering their stress about death(Peterson et al., 2010). In a subsequent study, Peterson found that African American women living with HIV relied on their spirituality and religiosity for emotional support, a means to supplement their self-, and a way to positively reframe their situations(Peterson, 2011). In these studies women attributed much of their positive perceptions to a belief that their churches supported a healthier sense of self in the face of HIV/AIDS and provided an opportunity to extend similar help to other members. Also, important to note, these women were more likely to believe their deity provided a sense of control over an initially devastating situation. This is in contrast to findings of studies of individuals who reported that spirituality was not an important aspect of their lives. Westgate suggested that these individuals would be more vulnerable to decreased levels of mental health, feelings of isolation, and hopelessness(Westgate, 1996). Spiritualty is an important means of coping with stressors for some women. Women's coping strategies are important in determining the psychological impact stress will have on individual. Individuals who are perceived as having poor coping strategies are less likely to complete tasks, including family care and may have more difficulty navigating the social environment(Gilmore, Osho, \& Heads, 2013).

Yet, given the importance of spirituality as a means of African American women's ability to cope with adversity, there is very little empirical research examining its impact on coping with changes in the family in the context of maternal HIV infection. Specifically, research does not exist that examines the moderating effect of spirituality on the relationship between maternal psychosocial factors and perceptions of family functioning. Therefore, this study will begin to explore the interactions among spirituality, depression, and family functioning. Specifically, the current study will determine under what condition is maternal depression negatively related to family functioning. Additionally, this study will address whether spirituality moderates the link between depression and family functioning.

\section{METHODS}

\section{Participants}

The participants in the current study included 70 HIV-positive women between the ages of 21 and 66 years old (mean age $=42.6$ ) from the Washington, DC Metro area. These women reported living with HIV for an average of 12.8 years. At least $10 \%$ of the women reported that their partner/spouse was also HIV-positive. Among the participants, six (8.6\%) indicated that their child(ren) were also HIV-positive. Twenty-six (37.1\%) women indicated that their employment-income had been impacted due to their HIV status. Sixty-four $(91.4 \%)$ of the mothers indicated that they had disclosed their HIV status to someone other than medical staff. Most women reported they told their parents $(68.6 \%)$, siblings $(70 \%)$, spouse or partner $(65.7 \%)$, child (ren) $(71.4 \%)$, and an extended family member such as a cousin, aunt, uncle, or close friend (68.6\%). Only six (8.6\%) of the participants disclosed their HIV status to their employer or school and twenty-four (34.3\%) told their minister or pastor.

\section{Procedures}

Data was collected as part of a larger project designed to identify psychosocial risk factors and protective factors related to mental health help seeking behaviors and healthy family environments among African American women 
living with HIV/AIDS. Women were recruited through the use of flyers announcing the study which were posted in HIV related clinics, centers, and support and through participant referrals. Scheduled surveys were administered on site at the health center, the support group meeting place, or a local university psychology department. Participants were given a consent form further detailing the project. Research staff explained the nature of the study and provided answers to questions regarding the study. The confidential nature of the study was emphasized; specifically the names of the women would not be associated with any of the data and the researchers would not share any of the participants' responses with anyone outside of the study. After completing the informed consent process, participants were given 60 to 75 minutes to complete the survey packet which included measures to assess depression, spirituality, disclosure concerns, attitudes about their family climate, child functioning, and help-seeking behaviors. As an incentive for participation, each woman was given a $\$ 20$ gift card.

\section{Measures}

\section{Depression}

The Center for Epidemiological Studies - Depression Scale (CES-D(Radloff, 1977); is a 20-item self-report measure of depressive symptoms (i.e., depressive affect, somatic symptoms, positive affect, and interpersonal relations). Each item is rated on a 4-point Likert scale ranging from 0 (rarely or none of the time- less than 1 day) to 3 (most or all of the time- 5 to 7 days). Total scores range from zero to 60 . Scores that are greater than or equal to 16 are considered to indicate significant levels of psychological distress. Specifically, scores ranging from 16 to 38 denote "at risk". Scores greater than 39 are often found in clinical populations. Internal consistency for the current sample was found to be $\alpha=.88$.

\section{Family Functioning}

The Family Environment Scale - Form Real (FES R(Moos \& Moos, 1983) is a measure used to assess current family environment including problems in family functioning, how the family has been affected by a transition, life crisis or change, family climate created by the parent, and risks for problems such as depression, substance abuse, or family violence. It consists of 90 true or false items, which contribute to ten subscales assessing three dimensions of family functioning: relationship (i.e., internal family functioning), personal growth (i.e., family functioning in relation to the larger society), and system maintenance. Standard scores $>50$, on most scales, are considered as positive perceptions about the family environment. However, a standard scores $>50$ on the Conflict scale represent a perceived increase in the level of family conflict and discord. For this sample, the alpha coefficient for the FES is .73 .

\section{Spirituality}

The Daily Spiritual Experience Scale-Short Form (DES; (Underwood \& Teresi, 2002); is a 6-item version of the original 16-item self-report scale that measures a person's perception of The Transcendent (e.g. God, the divine) in daily life situations. This scale addresses reported ordinary experiences of spirituality such as awe and joy that lifts one out of the mundane, as well as a sense of deep inner peace. Items are scored using a modified Likert scale with responses ranging from $1=$ many times a day to $6=$ never or almost never. Items one through four are reverse scored. Possible scores can range from 6 to 36 with higher scores reflecting more frequent daily spiritual experiences. For this sample, the alpha coefficient for the DES is .70.

\section{RESULTS}

Correlations, means, and standard deviations for the depression measure, spirituality measure, and family environment measures are summarized in Table 1. 
Table 1. Correlations, Means, and Standard Deviations for Measures ( $\mathrm{N}=70)$

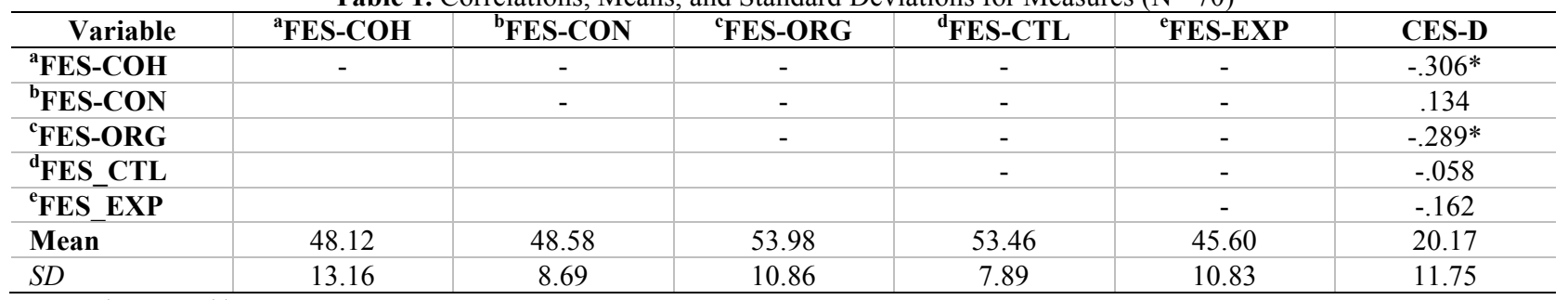

Note: $* \mathrm{p}<.05 . * * \mathrm{p}<.01$

Family Environment Scales (FES): ${ }^{\mathrm{a} C o h e s i o n ;}{ }^{\mathrm{b}} \mathrm{Conflict} ;{ }^{\mathrm{c}}$ Organization;

${ }^{\mathrm{d} C}$ Control; ${ }^{\mathrm{e}}$ Expressiveness

Results indicated that the level of depressive symptoms reported by the HIV infected mothers had a significant negative relationship with the degree of support that they believed family members provided (i.e., cohesion). A similar relationship was indicated in reference to the relationship of depressive symptoms to the degree of structure that exists within the family (i.e., organization). The moderating role of spirituality on the relationship between psychosocial factors and family functioning was examined utilizing steps recommended by Baron and Kenny(Baron \& Kenny, 1986). Participants were excluded from the analyses if they had missing data for any of the primary study variables. Therefore, 52 of the participants were included in the analyses.

A series of hierarchical regression analyses were conducted to examine how well depression predicts the different dimensions of family functioning and whether spirituality may moderate the relationship between depression and family functioning. The two predictors (depression and spirituality) and the interaction were entered into a regression model. A significant increase in $\mathrm{R}^{2}$ following the entry of the interaction term provides evidence of a moderation effect. The first hierarchical regression analysis sought to examine the relationship among depression, spirituality, and family cohesion. When entered into step one, depression was a significant predictor of family cohesion, $F(1,50)=4.449, p<.05, R^{2}=.082$. The addition of spirituality in the second step significantly improved the prediction $R^{2}$ change $=.076, F(1,49)=4.419, p<.05$. Spirituality accounted for $15.8 \%$ of the variance in family cohesion scores. In the third step, which consisted of adding the interaction between depressive symptoms and spirituality, the interaction term did not significantly increase the model, $R^{2}$ change $=.001, F(1,48)=3.021, p=.80$. The results indicate that the model as a whole is significant $R^{2}=.063, F(3,48)=3.021, p<.05$. However, the lack of additional variance when adding the interaction term in step 3 indicates that spirituality does not moderate the relationship between depression and family cohesion. See Table 2 for a summary of regression analyses for depression and spirituality predicting family cohesion.

Table 2. Summary of Hierarchical Regression Analyses for Depression and Spirituality Predicting Family Cohesion (N=52)

\begin{tabular}{l|c|c}
\hline \multicolumn{1}{c}{ FES Cohesion } & Beta & SE B \\
\hline Step 1: Depression (CES-D) & $-.286^{*}$ & .136 \\
\hline Step 2: Spirituality (DSE) & $.344^{*}$ & .164 \\
\hline Step 3: Depression X Spirituality & .035 & .155 \\
\hline
\end{tabular}

Notes: $* p<.05$

In attempting to predict family conflict, neither depression, spirituality, nor the interaction term significantly improved the model or had any significant effects. Similar results were found in a model for predicting family organization. Finally, results from a sequential regression analysis for predicting family control indicated neither predictor (depression, spirituality, and depression/spirituality interaction) had significant and unique effects on changes in how rules and procedures are used in families where maternal HIV is present.

\section{DISCUSSION}

The aim of this study was to assess the impact of spirituality on the relationship between depression and family functioning among African American mothers living with HIV/AIDS. It was assumed that given the significance of spirituality in coping with adversity, spirituality would serve as a psychosocial resource that would buffer the negative effects of depression on perceptions of the family environment in this sample of HIV-positive African American mothers. Specifically, it was expected that the HIV infected mothers spirituality would help minimize the 
potential negative impact of depressive feelings on the family relationships (e.g. decrease family conflict and increase family cohesion) and help maintain a healthy family structure (e.g. organization and control).

Although spirituality appeared to demonstrate an inverse relationship with depression among the participants, it did not prove to be a significant factor in moderating the relationship between depression, and family functioning (e.g. family conflict, organization and structure within the family). The relationship between spirituality and depression found in the current study is consistent with previous studies that demonstrated the value of having existential wellbeing or spirituality in order to promote psychological well-being(Coleman \& Holzemer, 1999).

Spirituality was found to significantly impact family relationships. More specifically, spirituality emerged as a significant predictor of how the participants perceived the level of family support received from other family members, i.e., family cohesiveness. Those mothers who reported high levels of spirituality also reported high levels of family cohesion. This is consistent with studies that suggest that spirituality is associated with positive interpersonal relationships(Mattis, 2000). Additionally, many of the women reported that they regularly attended religious services, forming church-based networks as another source of support. According to some researchers, support received from church members also provides emotional closeness, encouragement, and companionship, similar to family members(Taylor, Chatters, \& Levin, 2003; Taylor, Lincoln, \& Chatters, 2005). The sense of cohesiveness experienced from the church may then be transferred to the family environment, especially if the family also participates in religious activities.

It is important to note, that contrary to existing literature that depicted families affected by maternal HIV infection as dysfunctional(Miles, Burchinal, Holditch-Davis, Wasilewski, \& Christian, 1997; Pianta \& Egeland, 1994), the mothers who participated in this study did not indicate significant levels of family discord or dysfunction related to family expressiveness, conflict among family members, organization and structure of family activities and responsibilities, and the use of rules and procedures to family life in spite of their many challenges, including emotional distress. The African American mothers in this sample reported that their families were generally well functioning in spite of their emotional distress and environmental stressors (e.g., low SES, unemployment, and single parenthood). These results attest to the resiliency of these women and their families in the context of a family crisis partially facilitated by their spirituality.

Overall, these findings support the importance of spirituality in determining how African American mothers perceive their family climate in the context of maternal HIV infection. Spirituality is a transcendent belief that shapes how the family unit copes with crises; it supplies meaning in people's lives and is a key process in a family's ability to cope or adapt to challenges(Mackay, 2003; Walsh, 2006). In the case of African American mothers living with HIV, results suggest that their spirituality offers "clarity in [their] lives solace in distress; they render unexpected events less threatening and enable acceptance of situations that cannot be changed."(Mackay, 2003; Walsh, 2006) In spite of the many challenges faced by many of the mothers who participated in this study (e.g., single parenthood, unemployment, and poverty), they still appeared to describe normal family functioning. This sample of mothers living with HIV utilized their relationship with "God" and religiosity to cope with life stressors to decrease psychosocial distress.

Given the resiliency of these African American mothers, findings from the current study have significant implications for treatment planning and implementation for women described in this study in order to further support and strengthen their families. First, these findings support the need for ongoing assessment and interventions to assist HIV-positive mothers in decreasing reported levels of emotional distress associated with their seropositive status including feelings of shame, depression, guilt, and anxiety. Secondly, findings highlight the need for psychoeducation and support for not only the HIV-positive woman but also for members of her family, focusing on the impact of depression on family relationships and family structure. Finally, results from the current study continue to demonstrate the importance of spirituality in coping with family stress such as maternal illness, especially in this specific population. Specifically, findings support the relevance for additional research assessing the protective value of spirituality in assisting African American mothers living with HIV/AIDS reduce psychosocial stress and improve family relationships. 
Given the strengths of the current study, there are a few limitations that must be addressed. First, it is difficult to generalize findings from this study to other populations of African American mothers living with HIV given the small sample size and uniqueness of the sample. Many of the women who participated in the study were active participants in support groups and also took advantage of services offered by HIV/AIDS agencies. Additionally, their participation in the study may suggest they may have attained coping skills not available to women who do not participate in such services. Many African American women living with HIV/AIDS do not have the benefit of participating in organizations that provide emotional support due to fear of being rejected and the loss of their identity.

To address some of these issues, future research should place more effort on recruiting a larger, heterogeneous sample to include more women who are newly diagnosed with HIV. Including this sample may provide additional information regarding the impact of spirituality at the onset of living with HIV in the family relationships, family roles, and family responsibilities. This may prove to be a difficult task given the stigma attached to HIV and disclosure concerns. Additionally, the sample should include women from different ethnic groups to assess differences in the relationship of maternal psychosocial factors such as depression and spirituality on perceptions of family functioning. It would also be interesting to include child report measures to assess possible differences in perceptions of current family functioning in the context of a parent living with HIV. Although the participants generally described well-functioning families, the children of the participants may have a different perspective of the family climate as it relates to their mother's HIV status.

\section{AUTHOR BIOGRAPHIES}

Dr. Aisha Asby, is an Assistant Professor in the Department of Psychology at Prairie View A\&M University in Prairie View, Texas. She received her Ph.D. in Clinical Psychology from Howard University. Email: atasby@pvamu.edu

Dr. Angela Heads is an Assistant Professor in the Department of Psychiatry and Behavioral Sciences at the University of Texas Health Science Center at Houston (UTHealth). She received her Ph.D. in Counseling Psychology from Texas A\&M University and completed a Postdoctoral Fellowship in the Center for Neurobehavioral Research on Addictions at UTHealth. She is a licensed psychologist with clinical expertise in evidence-based treatments for substance use disorders, anxiety and depression and a specific interest in women's mental health issues. Email: angela.m.heads@uth.tmc.edu.

Dr. Joe Dickson is currently a tenure track Assistant Professor in the Department of Psychology at Prairie View A\&M University in Prairie View, Texas. He received his Ph.D. in Clinical Psychology from the University of Tennessee and completed his internship and postdoctoral training with Baylor College of Medicine and the Menninger Clinic. He has worked in several settings including: a psychiatric hospital, longterm residential mental healthcare facility for adolescents, juvenile court, residential facility for adjudicated youth, and university counseling centers. Email: jwdickson@pvamu.edu

\section{REFERENCES}

Antle, B. J., Wells, L. M., Robyn Salter, G., DeMatteo, D., \& King, S. M. (2001). Challenges of parenting for families living with HIV/AIDS. Social Work, 46(2), 159-169.

Armistead, L., \& Forehand, R. (1995). For whom the bell tolls: parenting decisions and challenges faced by mothers who are HIV seropositive. Clinical Psychology: Science and Practice, 2(3), 239-250.

Baron, R. M., \& Kenny, D. A. (1986). The moderator-mediator variable distinction in social psychological research: Conceptual, strategic, and statistical considerations. Journal of personality and social psychology, 51(6), 1173.

Clark, H. J., Lindner, G., Armistead, L., \& Austin, B.-J. (2004). Stigma, disclosure, and psychological functioning among HIVinfected and non-infected African-American women. Women \& health, 38(4), 57-71.

Coleman, C. L., \& Holzemer, W. L. (1999). Spirituality, Psychological Well-Being, and HIV Symptoms for African Americans Living With HIV Disease. Journal of the Association of Nurses in AIDS Care, 10(1), 42-50. doi: http://dx.doi.org/10.1016/S1055-3290(06)60231-8 
Gilmore, A. D., Osho, G. S., \& Heads, A. B. (2013). Stress, Anxiety, Depression And Psychological Responses Among African Americans: Empirical Investigation And Coping Strategies. American Journal of Health Sciences (AJHS), 4(3), 121130.

Mackay, R. (2003). Family resilience and good child outcomes: An overview of the research literature. Social Policy Journal of New Zealand, 98-118.

Mattis, J. S. (2000). African American women's definitions of spirituality and religiosity. Journal of Black Psychology, 26(1), 101-122.

Miles, M. S., Burchinal, P., Holditch-Davis, D., Wasilewski, Y., \& Christian, B. (1997). Personal, family, and health-related correlates of depressive symptoms in mothers with HIV. Journal of Family Psychology, 11(1), 23.

Moos, R., \& Moos, B. (1983). Clinical applications of the family environment scale. A sourcebook of marriage and family assessment, 253-273.

Murphy, D., Marelich, W., Stritto, M. D., Swendeman, D., \& Witkin, A. (2002). Mothers living with HIV/AIDS: mental, physical, and family functioning. AIDS care, 14(5), 633-644.

Newlin, K., Knafl, K., \& Melkus, G. D. E. (2002). African-American spirituality: A concept analysis. Advances in Nursing Science, 25(2), 57-70.

Pedersen, S., \& Revenson, T. A. (2005). Parental illness, family functioning, and adolescent well-being: a family ecology framework to guide research. Journal of Family Psychology, 19(3), 404.

Peterson, J. L. (2011). The case for connection: Spirituality and social support for women living with HIV/AIDS. Journal of Applied Communication Research, 39(4), 352-369.

Peterson, J. L., Johnson, M. A., \& Tenzek, K. E. (2010). Spirituality as a life line: Women living with HIV/AIDS and the role of spirituality in their support system. Journal of Interdisciplinary Feminist Thought, 4(1), 3.

Pianta, R. C., \& Egeland, B. (1994). Relation between depressive symptoms and stressful life events in a sample of disadvantaged mothers. Journal of consulting and clinical psychology, 62(6), 1229.

Radloff, L. S. (1977). The CES-D scale a self-report depression scale for research in the general population. Applied psychological measurement, 1(3), 385-401.

Sayles, J. N., Ryan, G. W., Silver, J. S., Sarkisian, C. A., \& Cunningham, W. E. (2007). Experiences of social stigma and implications for healthcare among a diverse population of HIV positive adults. Journal of Urban Health, 84(6), 814828.

Taylor, R. J., Chatters, L. M., \& Levin, J. (2003). Religion in the lives of African Americans: Social, psychological, and health perspectives: Sage Publications.

Taylor, R. J., Lincoln, K. D., \& Chatters, L. M. (2005). Supportive Relationships with Church Members Among African Americans*. Family Relations, 54(4), 501-511.

Tompkins, T. L. (2007). Parentification and maternal HIV infection: Beneficial role or pathological burden? Journal of Child and Family Studies, 16(1), 108-118.

Tompkins, T. L., Henker, B., Whalen, C. K., Axelrod, J., \& Comer, L. K. (1999). Motherhood in the context of HIV infection: Reading between the numbers. Cultural Diversity and Ethnic Minority Psychology, 5(3), 197.

Underwood, L. G., \& Teresi, J. A. (2002). The daily spiritual experience scale: Development, theoretical description, reliability, exploratory factor analysis, and preliminary construct validity using health-related data. Annals of Behavioral Medicine, 24(1), 22-33.

Walsh, F. (2006). Strengthening family resilience: Guilford Press.

Walulu, R. N. (2011). Role of spirituality in HIV-infected mothers. Issues in mental health nursing, 32(6), $382-384$.

Westgate, C. E. (1996). Spiritual wellness and depression. Journal of Counseling \& Development, 75(1), 26-35.

Yi, M. S., Mrus, J. M., Wade, T. J., Ho, M. L., Hornung, R. W., Cotton, S., . . Tsevat, J. (2006). Religion, spirituality, and depressive symptoms in patients with HIV/AIDS. Journal of General Internal Medicine, 21(S5), S21-S27. 
NOTES 